AGREGAT: Jurnal Ekonomi dan Bisnis

Vol. 2, No. 2, September 2018

http://journal.uhamka.ac.id/index.php/agregat

p-ISSN: 2580-3360 e-ISSN: 2581-2874

DOI: 10.22236/agregat_vol1/is4pp388-398

Hal 388-398

\title{
EFEK MORAL REASONING TERHADAP NIAT AUDITOR INTERNAL UNTUK MELAKUKAN WHISTLEBLOWING
}

\author{
Meita Larasati \\ Universitas Muhammadiyah Prof. DR. HAMKA \\ Email : meita.larasati91@gmail.com
}

Diterima: 3 Juni 2018; Direvisi: 7 Juni 2018; Disetujui: 25 Juni 2018

\begin{abstract}
The purpose of this study is to investigate the effect of moral reasoning on the intention of internal auditors to conduct whistleblowing. The respondents in this study using purposive sampling technique. The researchers choose a sample based on individuals who have work experience as internal auditors for one year and at least 21 years old. This study used a survey method using a questionnaire. The questionnaire was distributed to 70 internal auditors who worked on State University located in Yogyakarta. However, only 56 questionnaires can be used in this study. All questionnaire were analyzed using regression analysis. This study provides empirical evidence that moral reasoning has a positive effect on the intention of internal auditor behavior to blow the whistle.
\end{abstract}

Keyword: Whistleblowing, intention, moral reasoning, internal auditor

\begin{abstract}
Abstrak
Penelitian ini bertujuan untuk menginvestigasi pengaruh moral reasoning terhadap niat internal auditor untuk melakukan whistleblowing. Sampel dalam penelitian ini menggunakan teknik purposive sampling. Peneliti memilih sampel berdasarkan individu yang memiliki pengalaman kerja minimal satu tahun sebagai auditor internal dan berumur sekurang-kurangnya 21 tahun. Penelitian ini menggunakan metode survey dengan menggunakan kuesioner sebagai instrument penelitian. Kuesioner didistribusikan kepada 70 auditor internal yang bekerja pada semua Universitas Negeri yang berada di wilayah Yogyakarta. Namun, hanya 56 kuesioner yang dapat digunakan dalam penelitian ini. Semua kuesioner yang terkumpul dianalisis dengan menggunakan regresi berganda. Hasil penelitian ini membuktikan bahwa moral reasoning memiliki pengaruh positif terhadap niat internal auditor untuk melakukan whistleblowing.
\end{abstract}

Kata Kunci: Whistleblowing, niat, moral reasoning, auditor internal 


\section{PENDAHULUAN}

Pengungkapan tindakan kecurangan atau yang dikenal dengan istilah whistleblowing dalam beberapa tahun terakhir telah menjadi fenomena yang menarik perhatian dunia. Sekitar satu dekade terakhir, dunia digemparkan dengan terungkapnya kasus kecurangan yang dilakukan oleh perusahaan besar, seperti Enron dan Worldcom. Pada kasus Enron, kecurangan terletak pada laporan keuangan perusahaan yang dimanipulasi agar terlihat bahwa perusahaan memiliki kinerja yang baik. Laporan keuangan yang dibuat oleh perusahaan Enron sengaja dimanipulasi dengan cara melakukan mark up pada pendapatan perusahaan (academia.edu). Kecurangan tersebut membuat Enron yang tadinya merupakan salah satu perusahaan terbesar di dunia bisnis Amerika, seketika rutuh setalah kasus tersebut terungkap.

Praktik whistleblowing yang dilakukan oleh anggota organisasi atau perusahaan dikenal dengan istilah "si pengungkap aib". Pengertian dari "si pengungkap aib" adalah individu yang dengan gamblang dan sukarela membeberkan kecurangan yang terjadi atau adanya perilaku tidak etis dalam suatu organisasi. Whistleblowing adalah sebuah tindakan yang tidak hanya dilakukan berdasarkan niat semata, akan tetapi juga harus diwujudkan dalam tindakan ketika seorang karyawan dihadapkan dengan adanya kecurangan dalam perusahaan (Bateman dan Crant, 1993). Miceli dan Near (2002) mengatakan bahwa mayoritas para whistleblower pertama kali mengungkapkan kecurangan atau tindakan tidak etis kepada internal perusahaan sebelum mereka melaporkannya kepada publik. Menjadi whistleblower bukanlah hal yang mudah karena pasti akan selalu dihadapkan oleh berbagai konsekuensi. Alasan utama para whistleblower rela membayar ongkos personal yang begitu tinggi menjadi poin yang sangat menarik untuk diteliti. Aksi heroik para whistleblower pasti tidak akan pernah terlepas dari dilema etis yang dirasakan dalam lingkungan kerja mereka.

Tindakan untuk tidak melakukan whistleblowing dapat dikategorikan menjadi dua bentuk, yaitu "memilih untuk diam" (Gorta \& Forell, 1995) dan "tidak melakukan tindakan" (Rothschild \& Miethe,1999), walaupun ada kemungkinan timbul tindakan lain, namun kedua tindakan tersebut sudah dapat mewakili perilaku seseorang ketika menyaksikan adanya kesalahan dalam organisasi (Dworkin \& Callahan, 1991; Miceli \& Near, 1992; King, 2000;). Niat individu untuk melakukan whistleblowing adalah sebagai dasar kemungkinan individu tersebut untuk melakukan whistleblowing walaupun berada 
390 AGREGAT: Jurnal Ekonomi dan Bisnis

Vol. 2, No. 2, September 2018

http://journal.uhamka.ac.id/index.php/agregat

p-ISSN: 2580-3360 e-ISSN: 2581-2874

DOI: 10.22236/agregat_vol1/is4pp388-398

Hal 388-398

di bawah tekanan. Beberapa profesi memiliki keterkaitan yang sangat dekat dengan whistleblowing, seperti profesi akuntan dan auditor (internal mau pun eksternal). Mereka memiliki banyak kesempatan untuk mengungkap penyimpangan atau kecurangan yang terjadi bahkan sebelum efeknya menjadi besar dan sangat membahayakan kelangsungan hidup (going concern) perusahaan (Shawver dan Clements, 2012).

Dilema etis yang dihadapi oleh auditor internal dan eksternal berbeda. Auditor internal lebih sulit memutuskan untuk melakukan whistleblowing. Hal ini disebabkan karena auditor internal selalu dihadapkan dengan konflik kepetingan. Auditor Internal dituntut tanggung jawab dan loyalitas oleh organisasi tempat mereka bekerja. Peran auditor internal sangatlah besar untuk mengetahui dan melaporkan wrongdoing yang terjadi di Organisasi. Namun, terkadang ada ancaman yang membuat auditor internal lebih memilih untuk menyebunyikan temuannya. Oleh karena itu profesi akuntan dan auditor hendaknya memiliki moral reasoning agar dapat menyikapi dilema etis yang sering ditemui pada praktik kerja mereka. Beberapa penelitian terdahulu telah memberikan bukti bahwa moral reasoning memiliki pengaruh yang signifikan terhadap niat individu untuk melakukan whistleblowing dan akan berlanjut pada aksi mereka untuk melaporkan kecurangan tersebut (Miceli dan Near, 2005; Taylor and Curtis (2010). Secara kodrati, manusia diciptakan sebagai mahluk sosial yang tidak akan pernah terlepas dari moral dan norma-norma sosial dalam memutuskan suatu tindakan. Moralitas dapat diartikan sebagai suatu standar atau pedoman yang mengatur hak dan kewajiban dari hubungan manusia secara sosial (Rest, 1986).

Menurut Kohlberg (1981) moral reasoning merupakan penilaian nilai, sosial dan kewajiban yang mengikat individu dalam melakukan suatu tindakan. Moral reasoning adalah konsep dasar individu untuk menganalisa masalah sosial-moral dan menilai terlebih dahulu tindakan apa yang akan dilakukan (Rest, 1979). Dapat disimpulkan bahwa moral reasoning merupakan konsep dasar dan kemampuan individu untuk menganalisa keputusan dan menentukan suatu tindakan bermoral dalam menghadapi situasi sosial tertentu terutama ketika dihadapkan oleh suatu dilemma etis. Kohlberg (1981) menyatakan bahwa kapasitas moral reasoning individu dapat berkembang ketika individu tersebut mendapatkan tambahan struktur moral 
kognitif pada setiap level pertumbuhan moral. Teori Cognitive Moral Development yang dikembangkan oleh Kohlberg (1969) berdasarkan asumsi bahwa terdapat proses kognitif yang terlibat dalam penilaian moral yang berkembang. Kohlberg mengidentifikasikan tiga level perkembangan moral, yaitu: PreConventional, Conventional dan PostConventional atau Principled. Tiga level utama ini dapat berkembang sesuai dengan kondisi yang mereka hadapi, masing-masing dari level tersebut dibagi lagi menjadi dua tahap.

Level pertama adalah pertimbangan keputusan moralitas berdasarkan prospek hukuman (punishment), keputusan yang diambil hanya untuk menghindari suatu hukuman. Pada level kedua, individu mempresepsikan kebenaran dan kesalahan yang mutlak yang mengasumsikan bahwa hukum adalah hakim moralitas. Level ketiga merupakan level tertinggi, yaitu ketika individu membuat keputusan moral berdasarkan kontrak social untuk berprilaku tertentu dan mampu untuk mendahulukan etika diluar kepentingan sendiri atau kelompok. Berdasarkan teori Cognitive Moral Development, Kohlberg membuktikan bahwa pada setiap individu secara bertahap akan meningkatkan moral reasoning mereka dari tingkatan yang terendah sampai kepada tingkatan yang tertinggi. Gundlach et al. (2003) menyatakan bahwa moral reasoning dan retaliasi mempunyai peran yang signifikan dalam proses untuk melakukan whistleblowing. Hasil empiris dari beberapa penelitian terdahulu juga mendukung kedua faktor (retaliasi dan moral reasoning) tersebut dalam mempengaruhi keputusan seseorang untuk melakukan whistleblowing (Arnold and Ponemon, 1991; Brabeck, 1984; Brewer dan Selden, 1995; Chan dan Leung, 2006; Liyanarachi dan newdick, 2009; Miceli et al., 1991; Near dan Miceli, 1986).

Menurut Brabeck (1984) kemampuan seseorang untuk menyelesaikan atau mengintepretasikan dilema etis dipengaruhi oleh moral reasoningnya. Penelitian dari Rest dan Narvaes (1994) menunjukan bahwa semakin tinggi tingkat moral reasoning individu maka semakin besar kemungkinan untuk berperilaku etis. Pola pikir demikian senada dengan penelitian dari Arnold \& Ponemon (1991) yang menemukan bahwa moral reasoning seseorang akan mempengaruhi perilaku etisnya, orang yang memiliki moral reasoning yang rendah akan memiliki respon yang berbeda dibanding orang yang memiliki moral reasoning yang lebih tinggi jika dihadapkan dengan permasalahan etis. Arnold \& Ponemon (1991); Brabeck (1984); dan Ponemon \& Gabhart (1990) menemukan bahwa auditor 
392 AGREGAT: Jurnal Ekonomi dan Bisnis

Vol. 2, No. 2, September 2018

http://journal.uhamka.ac.id/index.php/agregat

p-ISSN: 2580-3360 e-ISSN: 2581-2874

DOI: 10.22236/agregat_vol1/is4pp388-398

Hal 388-398

dengan moral reasoning yang tinggi akan memiliki niat yang lebih tinggi dalam melakukan whistleblowing dibanding dengan auditor dengan moral reasoning yang lebih rendah. Penelitian yang dilakukan oleh Liyanarachchi dan Newdick (2009) konsisten dengan penelitian sebelumnya yang menyatakan bahwa, pada umumnya individu dengan tingkat moral reasoning yang tinggi akan melakukan whistleblowing dibandingkan dengan tingkat moral reasoning yang rendah. Penjelasan dari beberapa penelitian di atas menunjukan hasil yang konsisten terhadap moral reasoning dan niat individu untuk melakukan whistleblowing membuat peneliti ingin mengkonfirmasi kembali mengenai hubungan keduanya ketika diinvestigasi di Indonesia.

Moral reasoning yang memadai membuat individu tersebut lebih berperilaku etis, dan whistleblowing merupakan salah satu perilaku yang beretika. Berdasarkan pola perilaku individu terkait tingkatan moral reasoning yang dimilikinya, maka niat perilaku individu untuk melakukan whistleblowing lebih tinggi pada individu yang memiliki moral reasoning yang lebih tinggi.

\section{METODE PENELITIAN}

Penelitian ini merupakan penelitian kuantitatif. Hartono (2013), penelitian kuantitatif adalah penelitian yang dilakukan dengan mengumpulkan data yang berupa angka, atau data berupa kata-kata atau kalimat yang dikonversi menjadi data yang berbentuk angka. Metoda yang digunakan dalam penelitian ini adalah survey dengan menyebarkan kuesioner kepada responden yang sesuai dengan tujuan dari penelitian ini.

Pemilihan sampel dalam penelitian ini dilakukan dengan cara menetapkan sampel berdasarkan kriteria tertentu sesuai dengan tujuan penelitian. Penggunaan teknik pengumpulan sampel seperti ini lebih dikenal dengan nama purposive sampling. Sampel yang dipilih dalam penelitian ini adalah para auditor internal yang bekerja di Universitas Negeri yang berada di Yogyakarta. Kriteria sampel dalam penelitian ini adalah auditor internal yang telah memiliki pengalaman bekerja minimal satu tahun dan minimal berusia 21 tahun.

Responden yang dipilih dalam penelitian ini adalah auditor internal yang bekerja pada Universitas Negeri di wilayah Yogyakarta. Kuesioner yang dikirimkan berjumlah 70 kuesioner dengan jumlah kuesioner yang dapat digunakan sebanyak 56 kuesioner. Peneliti melakukan pilot test 
Sebelum menyebarkan kuesioner kepada auditor internal di Universitas Negeri yang berlokasi di Yogyakarta. Hal ini ditujukan untuk melihat sejauh mana responden memahami isi dari kuesioner penelitian ini. Pengujian data dalam penelitian ini melewati beberapa tahapan, yaitu tabulasi jawaban dari seluruh responden yang dilakukan dengan perhitungan profil responden, statistik deskriptif, uji kualitas data, dan uji asumsi klasik. Pengujian hipotesis dalam penelitian ini menggunakan metode analisis regresi. Metode ini digunakan karena peneliti ingin mengetahui pengaruh antara moral reasoning terhadap niat auditor internal untuk melakukan whistleblowing. Peneliti menggunakan software SPSS 21 (Statistical Product and Service Solution) untuk mengolah data dala penelitian ini.

Dalam penelitian ini moral reasoning diukur dengan menggunakan Definig Issue test (DIT), menggunakan instrumen yang dikembangkan oleh Welton et al (1994), dengan mengikuti pola instrumen DIT dari Rest (1979). Instrumen tersebut juga telah digunakan dalam penelitian Liyanarachchi dan Newdick (2009). Intrumen tersebut dinilai paling sesuai ketika digunakan untuk mengukur persepsi mahasiswa akuntansi dan profesi akuntan (Welton et al., 1994) dan paling sering digunakan dalam penelitian yang terkait dengan whistleblowing
(Liyanarachchi dan Newdick, 2009). Instrumen terdiri dari tiga skenario yang merefleksikan aspek lingkungan kerja akuntan. Namun, dengan berbagai pertimbangan, peneliti hanya memakai satu skenario. Pertama, peneliti berasumsi dari ketiga skenario DIT tersebut, hanya satu kasus yang relevan untuk digunakan dalam penelitian ini. Kedua, untuk meminimalisir adanya non-respon bias pada penelitian ini. Ketiga, peneliti menjaga agar instrumen penelitian tidak terlalu panjang agar responden tidak menghabiskan banyak waktu dalam pengisian instrumen dan akan membuat jenuh responden. Partisipan diminta untuk mengevaluasi pernyataan pada lima skala likert (1= sangat tidak mungkin, $2=$ tidak mungkin, $3=$ cukup mungkin, $4=$ mungkin, 5= sangat mungkin) dan mengisi pada kolom yang telah disediakan.

Pengukuran variabel whistleblowing dalam penelitian ini mengadaptasi instrumen kasus yang dirumuskan oleh Schultz et al (1993). Responden diminta untuk menilai niat untuk melakukan whistleblowing dengan skala Likert lima-poin untuk tiap skenario (1= sangat tidak mungkin, $2=$ mungkin, $3=$ cukup mungkin, $4=$ mungkin, 5= sangat mungkin).

\section{HASIL DAN PEMBAHASAN}

Pengujian Validitas dalam penelitian ini menggunakan Confirmatory Analysis 
394 AGREGAT: Jurnal Ekonomi dan Bisnis

Vol. 2, No. 2, September 2018

http://journal.uhamka.ac.id/index.php/agregat

p-ISSN: 2580-3360 e-ISSN: 2581-2874

DOI: 10.22236/agregat_vol1/is4pp388-398

Hal 388-398

Factor (CFA). Ketentuan validitas item pertanyaan diperoleh dari KMO MSA > 0.5 dan signifikansi $<0.05$. sumbu diagonal anti-image correlation harus > 0.5 dan hanya membentuk 1 faktor dalam komponen component matrix dengan melihat factor loading. Nilai dari KMO MSA dan Bartlett's Test dapat dilihat pada tabel 1. Hasil analisis menunjukan bahwa nilai Kaiser-Meyer-Olkin-Measure of Sampling Adequacy (KMO-MSA) adalah $0.513>0.5$ sehingga dapat dilakukan analisis faktor. Begitu juga dengan nilai Bartlett's Test of Sphericity memiliki signifikansi 0.000 , maka dapat dinyatakan bahwa uji analisis faktor dapat dilanjutkan.

Hasil analisis menunjukan bahwa nilai Kaiser-Meyer-Olkin-Measure of Sampling Adequacy (KMO-MSA) adalah $0.513>0.5$ sehingga dapat dilakukan analisis faktor. Begitu juga dengan nilai Bartlett's Test of Sphericity memiliki signifikansi 0.000, maka dapat dinyatakan bahwa uji analisis faktor dapat dilanjutkan. Pengintepretasian analisis faktor melalui factor rotation. Metode yang digunakan oleh peneliti dalam merotasi faktor-faktor tersebut adalah varimax. Hasil rotasi faktor dari variable penelitian ini dapat dilihat pada tabel 2 .
Dari Tabel 2 hasil rotasi menunjukan bahwa indiktor WB1 sampai WB4 mengelompok pada faktor 2 sedangkan MR1 sampai MR12 mengelompok pada faktor 1. Pengelompokan masing-masing indikator dengan masing-masing faktor, maka dapat disimpulkan bahwa semua indikator dikatakan valid karena masingmasing konstruk mengelompok berdasarkan variable tersebut. Pengujian reliabilitas dalam penelitian ini menggunakan uji statistik dengan melihat nilai Cronbach's Alpha untuk setiap konstruk. Konstruk tersebut dapat dikatakan reliabel jika nilai Cronbach's Alpha > 0,60 sehingga dianggap kuesioner dapat diandalkan (Hair et al., 2010).

Instrument whistleblowing dalam penelitian ini dinyatakan reliable karena memiliki nilai Cronbach's Alpha $0.880>$ 0.60. Instrument moral reasoning dalam penelitian ini dinyatakan reliable karena memiliki nilai Cronbach's Alpha $0.918>$ 0.60 Setelah seluruh item pertanyaan dinyatakan valid dan reliable maka peneliti melanjutkan pengujian untuk menguji hipotesis satu yaitu pengaruh moral reasoning terhadap niat auditor internal untuk melakukan whistleblowing. 
Tabel 1

KMO dan Bartlett's Test

\begin{tabular}{|l|l|r|}
\hline \multicolumn{2}{|l|}{ Kaiser-Meyer-Olkin-Measure of } & \\
Sampling Adequacy & 0.513 \\
\hline Bartlett's Test of & Approx. Chi- & 2.174 \\
Sphericity & Square & 3 \\
\hline
\end{tabular}

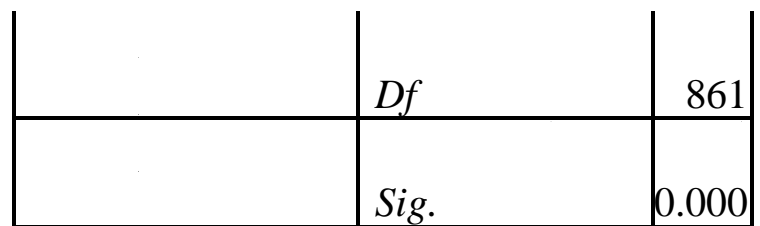

Sumber: Data primer yang diolah, 2015

Tabel 2

Rotated Component Matrix

\begin{tabular}{|c|c|c|}
\hline \multirow{2}{*}{} & \multicolumn{2}{|c|}{ Component } \\
\hline & $\mathbf{1}$ & $\mathbf{2}$ \\
\hline WB 1 & & 0.786 \\
\hline WB 2 & & 0.807 \\
\hline WB 3 & & 0.814 \\
\hline WB 4 & & 0.664 \\
\hline MR 1 & 0.705 & \\
\hline MR 2 & 0.690 & \\
\hline MR 3 & 0.794 & \\
\hline MR 4 & 0.646 & \\
\hline MR 5 & 0.669 & \\
\hline MR 6 & 0.595 & \\
\hline MR 7 & 0.821 & \\
\hline MR 8 & 0.815 & \\
\hline MR 9 & 0.754 & \\
\hline MR 10 & 0.676 & \\
\hline MR 11 & 0.832 & \\
\hline MR 12 & 0.630 & \\
\hline Sun: Dat pring & \\
\hline
\end{tabular}

Sumber: Data primer yang diolah, 2015

Tabel 3

Hasil Uji t

\begin{tabular}{|c|c|c|c|c|}
\hline Variabel & Koef Regresi & $\mathrm{t}_{\text {hitung }}$ & $\mathrm{t}_{\text {tabel }}$ & Sig \\
\hline Konstanta & $\mathbf{3 . 2 8 7}$ & & & \\
\hline $\begin{array}{c}\text { Moral } \\
\text { reasoning }\end{array}$ & $\mathbf{0 . 2 5 9}$ & $\mathbf{2 . 3 3 6}$ & $\mathbf{1 . 6 7 6}$ & $\mathbf{0 . 0 2 3}$ \\
\hline
\end{tabular}

Sumber: Data primer yang diolah, 2015

Berdasarkan hasil penelitian yang telah moral reasoning sebesar $2.336>1.676$

dilakukan menunjukan bahwa hipotesis satu yaitu moral reasoning memiliki pengaruh positif terhadap niat auditor internal untuk melakukan whistleblowing diterima. Hasil pengujian menunjukan bahwa nilai t variabel dengan signifikansi 0.023 dapat dilihat pada tabel 3. Hal ini menunjukan bahwa moral reasoning memiliki pengaruh positif terhadap niat individu untuk melakukan whistleblowing. Individu dengan tingkat 
396 AGREGAT: Jurnal Ekonomi dan Bisnis

Vol. 2, No. 2, September 2018

http://journal.uhamka.ac.id/index.php/agregat

p-ISSN: 2580-3360 e-ISSN: 2581-2874

DOI: 10.22236/agregat_vol1/is4pp388-398

Hal 388-398

moral yang lebih tinggi mempunyai niat yang lebih besar untuk melakukan whistleblowing. Hasil dari pegujian $\mathrm{H} 1$ dalam penelitian ini sejalan dengan beberapa penelitian terdahulu yang menyebutkan bahwa auditor dengan moral reasoning yang tinggi akan memiliki niat yang lebih tinggi untuk melakukan whistleblowing sebaliknya dengan auditor yang memiliki moral reasoning yang rendah (Arnold \& Ponemon; 1991, Brabeck; 1984, Ponemon \& Gabhart; 1990). Penelitian terdahulu juga konsisten dengan penelitian yang dilakukan oleh Liyanarachchi dan Newdick (2009) yang menyatakan bahwa, pada umumnya individu dengan tingkat moral reasoning yang tinggi cenderung melakukan whistleblowing dibandingkan dengan tingkat moral reasoning yang rendah.

\section{SIMPULAN}

Tujuan dari penelitian ini adalah untuk menguji pengaruh moral reasoning terhadap niat auditor internal untuk melakukan whistleblowing. Hasil penelitian ini membuktikan bahwa tingkat moral reasoning mempunyai pengaruh positif yang signifikan terhadap niat individu untuk melakukan whistleblowing. Jadi, individu dengan tingkat moral reasoning yang tinggi mempunyai niat yang lebih besar untuk melakukan whistleblowing daripada individu dengan tingkat moral reasoning yang rendah.

Penelitian ini hadir bukan tanpa adanya limitasi. Limitasinya adalah penelitian ini masih menggunakan subyek penelitian yang tidak terlalu luas, yakni auditor internal yang bekerja di Universitas Negeri yang berada di Yogyakarta. Penelitian ini memiliki kontribusi dalam perluasan literatur dan melengkapi penelitian sebelumnya yang berkaitan dengan whistleblowing. Penelitian ini diharapkan bermanfaat sebagai acuan untuk lembaga pendidikan agar lebih menekankan pendidikan etika bisnis kepada mahasiswa supaya kedepannya dapat bertindak lebih beretika. Hasil penelitian ini diharapkan dapat menjadi dasar pertimbangan bagi organisasi untuk mulai membentuk whistleblowing sistem, hal ini ditujukan untuk pencegahan fraud dan wrongdoing.

\section{REFERENSI}

Arnold, D., and L. Ponemon. (1991). Internal Auditors Perception of Whistle-Blowing and The Influence of Moral Reasoning: An Experiment. Auditing: A journal of Practice \& Theory. 10(2): 1-15.

Bateman, T. S., and Crant, J. M. (1993).

The Proactive Componenent of 
Organizational Behavior. Journal of Organizational Behavior. 14(2): 103118.

Brabeck, M. M. (1984). Ethical Characteristics of Whistle-Blowers. Journal of Research in Personality. 18: 41-53.

Brewer, G. A. and S. C. Selden. (1995). Whistle Blowing in the Federal Civil Service: New Evidence of the Public Service Ethics?. Revised Version of the Paper Presented at the Annual Meeting of the America Political Science Association. (Chicago, IL)

Chan, S. Y. and P. Leung. (2006). The Effects of Accounting Students Ethical Reasoning and Personal Factors on Their Ethical Sensitivity. Managerial Auditing Journal. 21: 436-457.

Dworkin, T.M. and E.S. Callahan. (1991). Internal Whistleblowing: Protecting the Interests of the Employee, the Organization and Society. American Business Law Journal. 29: 267-308.

Gorta, A. and S. Forell. (1995). Layers of Decision Linking Social Definitions of Corruption and Willingness to Take Action. Crime, Law, \& Social Change. 23: 315-343.

Gundlach, M. J. et al. (2003). The Decision to Blow the Whistle: A Social
Information Processing Framework. Academy of Management Review (Janury): 107-123.

Hair, J.F., et al. (2010). Multivariate data analysis. 7th edition. New Jersey : Pearson Education Inc.

Hartono, Jogiyanto. (2013).

Metodologi Penelitian Bisnis.

Edisi 6. BPFE : Yogyakarta.

King, G. 2000. The Implications of Differences in Cultural Attitudes and Styles of Communication on Peer Reporting Behavior. Cross Cultural Management - An International Journal. 7(2): 11-17.

Kolhberg, L. (1969). Continuities and Discontinuities in Childhood and Adult Moral Development. Human Development. 12(2): 93-120.

Kohlberg, L. (1981). The Philosophy of Moral Development, Moral Stage and Idea of Justice. San Francisco : Harper and Row.

Liyanarachchi, G., and Newdick, C. (2009). The Impact of Moral Reasonin and Retaliation on Whistle-Blowing: New Zealand Evidence. Journal of Business Ethic. 89: 37-57

Miceli, M. P., J. B. Dozier and Near. Near, J. P. (1991), Blowing the Whistle on Data-Fudging: A Controlled Field 
398 AGREGAT: Jurnal Ekonomi dan Bisnis

Vol. 2, No. 2, September 2018

http://journal.uhamka.ac.id/index.php/agregat

p-ISSN: 2580-3360 e-ISSN: 2581-2874

DOI: 10.22236/agregat_vol1/is4pp388-398

Hal 388-398

Experiment. Journal of Applied Social

Psychology. 21(4): 271-295.

Miceli, M. P. and Near. J. P. (1992).

Blowing the Whistle - The Organizational and Legal Implications for Companies and Employes. New York, NY: Lexington Books

Miceli. M. P. \& Near, J. P. (2002). What Makes Whistle-Blower Effective? Three Field Studies. Human Relation, $55,455-479$.

Ponemon, L. (1994). A Comment On

"Whistle -Blowing" As An Internal

Control Mechanism: IndividualAnd

Organizational Considerations.

Auditing: A Journal of Practice \& Theory (Fall). 118-130.

Rest, J. (1986). Moral Development. Advance in Research and Theory. New York. Praeger.

Rest, J. (1979). Development In JudgingMoral Issues. Minneapolis, MN: University of Minnesota Press.

Rest, J. R. \& Narvaez, D. (1994). Moral Development in Prefessions. New Jersey: Lawrence Erlbaum Associates Pub

Rothschild, J. and Miethe, T. D. (1999). Whistle-blower Disclosure and
Management Rataliation. Work \& Occupations. 26(1): 107-128.

Schultz, J. J., D. A. Johnson,. D. Morris and S. Dyrnes. (1993). An Investigation of the Reporting of Questionable Acts in an International Setting. Journal of Accounting Research. 31: 75-103.

Shawver, T., and Clements, L. H. (2012). How Do Emotions Affect Ethical Evaluation For Accountans. Journal of Forensic and Investigating 4.

Taylor, E.Z., and Curtis, M.B. (2010). An Examination of the Layers of Workplace Influences in Ethical Judgments: Whistleblowing Likelihood and Preseverance in Public Accounting. Journal of Business Ethics. 93: 21-37.

Welton, R. E., J. R. Davis and M. LaGrone. (1994). Promoting the Moral Development of Accounting Graduate Students: An Instructional Design and Assessment. Accounting Education. International Journal. 3(1): 35-50. 